\title{
Do erythropoietin and iron really decrease blood transfusion in surgical patients? A trial sequential analysis
}

\author{
Stephen Su Yang, MDCM, FRCPC (1) · Nilesh Ramdoyal, MDCM, BPharm
}

Received: 25 October 2019/Revised: 12 December 2019/Accepted: 13 December 2019/Published online: 8 January 2020

(C) Canadian Anesthesiologists' Society 2020

\section{To the Editor,}

Preoperative anemia is a risk factor for postoperative mortality in surgical patients. ${ }^{1}$ This is often treated during the perioperative period by packed red blood cell (pRBC) transfusion. Nevertheless, liberal pRBC transfusion has not been shown to improve perioperative outcomes. ${ }^{2}$ Moreover, in rare cases, pRBC transfusion is accompanied by severe or life-threatening complications, such as acute hemolytic reaction due to $\mathrm{ABO}$ incompatibility, graft- $v s$-host disease, transfusionassociated circulatory overload, and transfusion-related acute lung injury. ${ }^{3}$ Therefore, there is a need to investigate potential treatments of preoperative anemia that might both minimize pRBC transfusion and improve patient outcomes. A possible option includes the use of preoperative iron and erythropoiesis-stimulating agents (ESAs). In a recent issue of the Journal, Kei et al. reported a systematic review and meta-analysis of 25 randomized-controlled trials (RCTs) addressing preoperative administration of erythropoietin and iron therapy to reduce red blood cell transfusion in surgical patients. ${ }^{4}$ The number of participants in the included trials ranged from 27 to 693 . A random-effects model was used for the meta-analysis and the overall heterogeneity was $\mathbf{7 8 \%}$. Their primary outcome showed

S. S. Yang, MDCM, FRCPC ( $₫) \cdot$ N. Ramdoyal, MDCM, BPharm

Department of Anesthesia, McGill University, Montreal, QC,

Canada

e-mail: stephen.yang@mail.mcgill.ca that ESA and iron therapy significantly reduced perioperative $\mathrm{pRBC}$ transfusion compared with iron therapy alone (risk ratio, $0.57 ; 95 \%$ confidence interval, 0.46 to 0.71$){ }^{4}$

In a RCT, a sample size calculation is necessary to determine if the results are conclusive or not. Metaanalyses can share the same weaknesses as RCTs on which they are based. Type I and type II errors present in an RCT will be transferred to any subsequent meta-analysis. Even when multiple RCTs are combined in a meta-analysis, the total "information size" may still be insufficient. Trial sequential analysis (TSA) estimates the "required information size" using cumulative random-effects methods to combine RCTs in a meta-analysis. It uses the same principle as a sample size calculation for an RCT, but also accounts for heterogeneity. ${ }^{5}$ A TSA creates thresholds to determine the impact of multiple testing and amount of information present in the meta-analysis. With this tool, we can determine if the estimated effect is sufficiently large that the conclusion is unlikely to change if further trials are added to the meta-analysis. ${ }^{5}$

We performed two analyses using TSA methodology with the data reported in the article by Kei et al. using TSA Viewer version 0.9.5.10 beta (Copenhagen Trial Unit; Denmark). We assumed a relative risk reduction of $25 \%$, with an alpha of 0.05 and a power of $80 \%$. The optimal information size was determined to be 333 patients. A second TSA using a power of $90 \%$ determined an optimal information size of 1,132 patients (Figure). In both these analyses, the meta-analysis that Kei et al. performed has exceeded the optimal information size. Therefore, the effectiveness of preoperative administration of iron and ESA compared with iron alone to reduce perioperative blood transfusion appears conclusive based on TSA. 


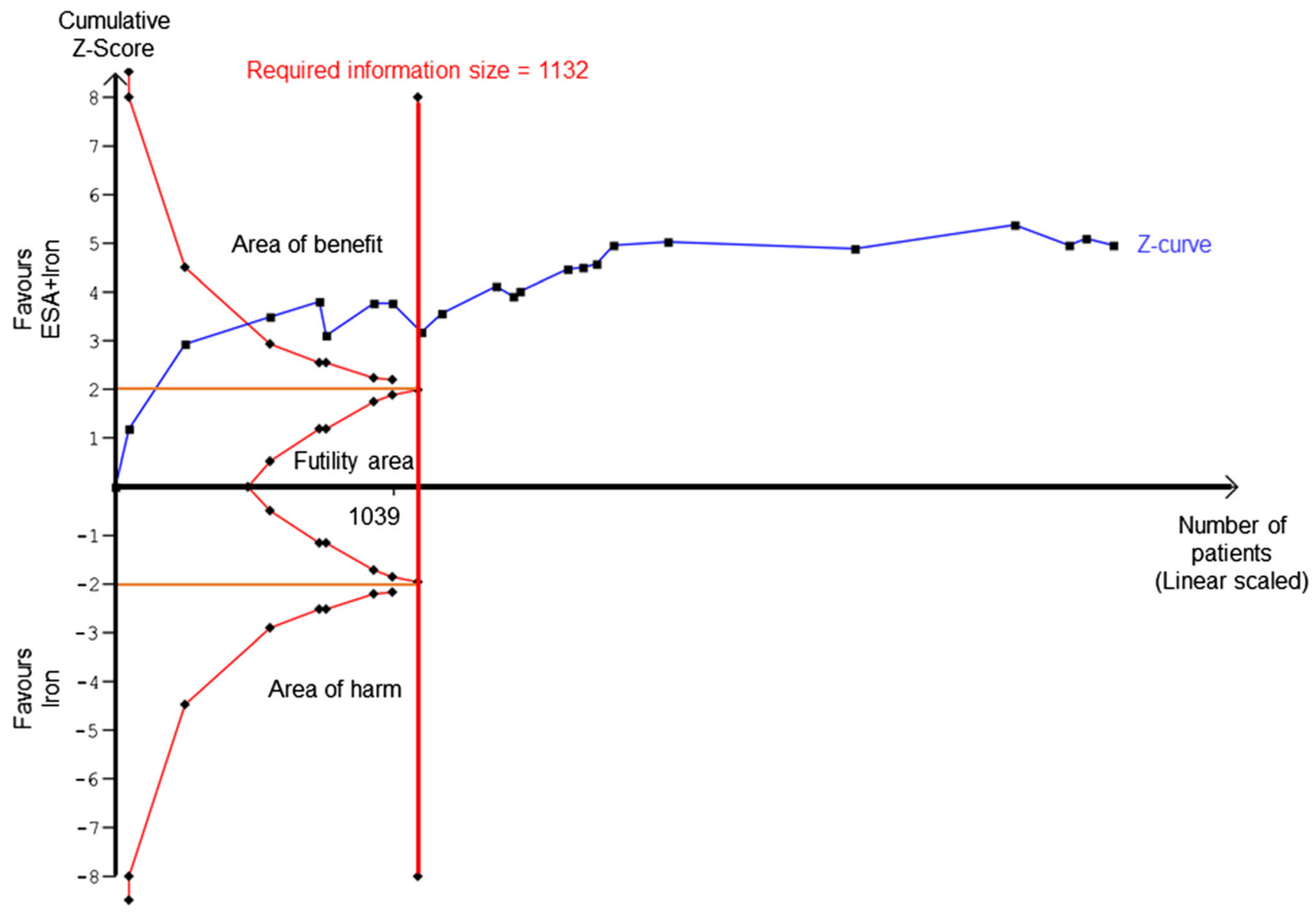

Figure Trial sequential analysis with $90 \%$ power on perioperative blood transfusion. The $\mathrm{x}$-axis represents the accumulated number of participants. The $y$-axis represents the $\mathrm{Z}$-value with statistical summary of accrued data. The horizontal orange line represents the conventional threshold for statistical significance (corresponding to $P$ $=0.05)$. The blue line represents the cumulative $\mathrm{Z}$ curve and the

\section{Conflicts of interest None.}

\section{Funding statement None.}

Editorial responsibility This submission was handled by Dr. Hilary P. Grocott, Editor-in-Chief, Canadian Journal of Anesthesia.

\section{References}

1. Fowler AJ, Ahmad T, Phull MK, Allard S, Gillies MA, Pearse RM. Meta-analysis of the association between preoperative anaemia and mortality after surgery. Br J Surg 2015; 102: 1314-24. accumulated amount of information added by each trial, depicted by a square dot. The red diagonal line inside the orange horizontal line represents the futility boundaries. The curved line on the top and bottom represent the sequential analysis threshold for statistical significance. ESA = erythropoiesis-stimulating agents.

2. Shehata $N$, Mistry $N$, da Costa BR, et al. Restrictive compared with liberal red cell transfusion strategies in cardiac surgery: a meta-analysis. Eur Heart J 2019; 40: 1081-8.

3. Frazier SK, Higgins J, Bugajski A, Jones AR, Brown MR. Adverse reactions to transfusion of blood products and best practices for prevention. Crit Care Nurs Clin North Am 2017; 29: 271-90.

4. Kei T, Mistry N, Curley $G$, et al. Efficacy and safety of erythropoietin and iron therapy to reduce red blood cell transfusion in surgical patients: a systematic review and metaanalysis. Can J Anesth 2019; 66: 716-31.

5. Shah A, Smith $A F$. Trial sequential analysis: adding a new dimension to meta-analysis. Anaesthesia 2020; 75: 15-20.

Publisher's Note Springer Nature remains neutral with regard to jurisdictional claims in published maps and institutional affiliations. 